\title{
TUMOUR-LIKE CHAGASIC ENCEPHALITIS IN AIDS PATIENTS
}

\section{An atypical presentation in one of them and outcome in a small series of cases}

\author{
Roberto E.P. Sica', Gisella Gargiullo², Cristina Papayanis ${ }^{3}$
}

Chagas' disease is an intracellular parasitic infection owed to a protozoarium, the Trypanosoma cruzi', affecting a large population in Latinamerica. Within the region 15 to 16 million people are infected ${ }^{2}$.

The worldwide pandemia, due to the infection of the HIV 1 virus, also affects Latinamerican countries. The number of patients with this condition in Central and South Americas amounts to 1.6 million persons ${ }^{3,4}$. Therefore, both illnesses overlap in a broad geographical area and may coincide in the same patient.

The HIV infection, which causes the AIDS syndrome, impairs the immunological system and predisposes to the appearance of opportunistic infections, which may have been hosted unnoticed by the patient until then. Therefore, Chagas' disease, which is a dormant infection in most patients ${ }^{5}$, may reactivate if the immunological surveillance wanes off as the consequence of the viral insult. Along the last years we $\mathrm{e}^{6,7}$ and others ${ }^{8-10}$ found patients afflicted by AIDS, who developed brain lesions yielded by the Trypanosoma cruzi.

The present communication describes three further patients with this condition; one of them is unique because his clinical, radiological and immunological findings differ from those previously reported in the literature.

\section{CASES}

Patient 1

A 28-years-old male. Ten days before admission, he noted progressive weakness on the left side of his body followed by seizures on the same side which started on his upper limb and spread to the left lower limb, lasting 30-40 seconds. The seizures appeared 3 days before admission with a frequency of one per day. Simultaneously, he developed a throbbing bilateral headache. He also referred a weight loss of about $20 \mathrm{Kg}$ along the last four months.

On clinical examination he presented a left-sided hemiparesis with hyperactive reflexes. Ordinary laboratory tests were unremarkable, except for a very low count of CD4+ lymphocytes, which amounted to 70 cells $/ \mathrm{mm}^{3}$. Serum ELISA and Western Blot were positive for HIV infection and an indirect immunofluorescence assay (IIA) for Toxoplasmosis was positive as well. Serological tests for Chagas' disease (IIA, ELISA) and a search for trypomastigotes in blood were negative.

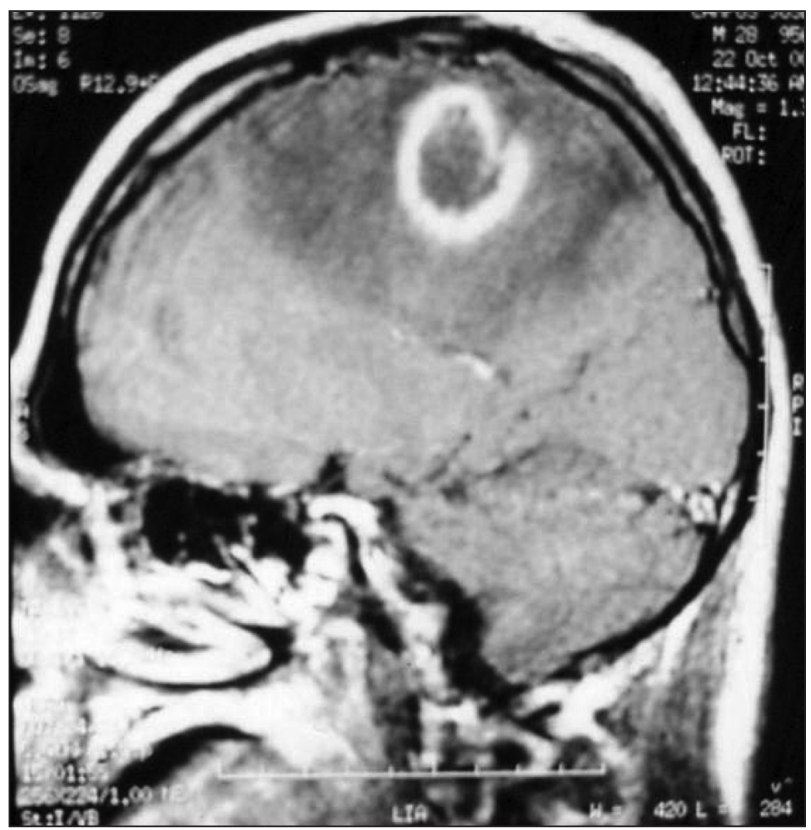

Fig 1. Patient 1. MRI showing a round lesion at the right parietal lobe surrounded by an enhanced gadolinium ring and oedema.

\section{ENCEFALITIS CHAGÁSICA PSEUDOTUMORAL EN PACIENTES CON SIDA: PRESENTACIÓN ATÍPICA EN UNO DE ELLOS E HISTORIA DE LA ENFER-} MEDAD EN UNA PEQUEÑA SERIE DE CASOS

División Neurología, Hospital Ramos Mejía, Facultad de Medicina, Universidad de Buenos Aires, Buenos Aires, Argentina: 'Emeritus Profesor, Buenos Aires University, School of Medicine, Buenos Aires University; ${ }^{2}$ Schollar, Consejo Nacional de Ciencia y Técnica (CONICET); ${ }^{3}$ Schollar, School of Medicine, Buenos Aires University. Funding: This investigation has been funded by the Goverment of the City of Buenos Aires.

Received 22 August 2008, received in final form 29 September 2008. Accepted 10 October 2008.

Dr. Roberto E.P. Sica - Secretaría de Ciencia y Técnica / Facultad de Medicina / Universidad de Buenos Aires - Paraguay 2155 - 1121 Buenos Aires, Argentina.E-mail: rsica@fmed.uba.ar 


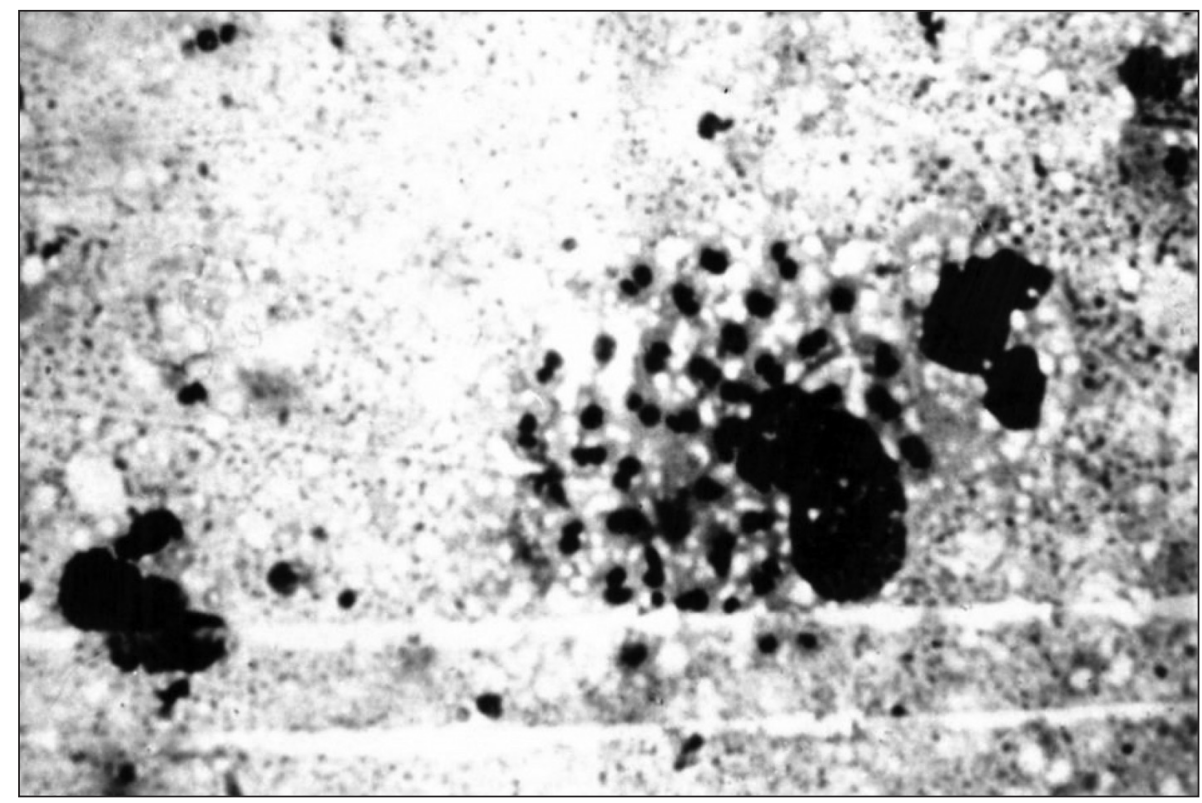

Fig 2. Patient 3. Biopsy of the right brain parietal lobe nodular lesion showing a macrophage filled with amastigotes (hematoxilin-eosin, magnification $\times 400$ ).

A brain magnetic resonance (MRI) disclosed a rounded image located at the parietal lobe, which was surrounded by digital-like oedema pushing aside the lateral ventricle; when gadolinium was administered an enhanced ring, encompassing the whole lesion, appeared (Fig 1).

Assuming that the lesion was due to toxoplasmosis infection the patient was put on pyrimethamine $100 \mathrm{mg} /$ day, clindamycin $600 \mathrm{mg} /$ qid and leucovorin $15 \mathrm{mg} /$ day. By day $12^{\text {th }}$ after treatment, no improvement of his clinical condition was observed; therefore, it was decided to obtain a biopsy of his brain lesion. Histological examination of the specimen showed necrotic tissue and macrophages filled with amastigotes.

The diagnosis of Chagas' disease was done and treatment with Benznidazol, $5 \mathrm{mg} / \mathrm{kg} /$ day, and antiretroviral therapy were started. The patient continued to deteriorate and died 50 days after the beginning of the therapy. Autopsy was not permitted.

\section{Patient 2}

A 51-years-old male. He came to the clinical office complaining of language disturbances, visual defects and weakness on the right side of his body. All the symptoms appeared about ten to fifteen days before his assessment and were slowly progressive.

On clinical examination he showed global aphasia, right hemianopia, right mild hemiparesis and spasticity.

Regular laboratory tests disclosed a low number of CD4+ lymphocytes amounting to $46 \mathrm{cells} / \mathrm{mm}^{3}$. Serum ELISA and Western Blot for HIV infection were positive. Serum tests for Toxoplasmosis and Chagas' disease were positive as well. However, trypomastigotes within the blood were not found.

MRI showed several, spontaneouly enhanced rounded lesions on T1-weighted imaging, probably due to blood in their cores, distributed along the whole brain, mainly at the boundery between the cortex and the white matter, surrounded by oedema.

The assumption of toxoplasmosis was done and appropriate treatment was started. At the $4^{\text {th }}$ day after treatment the patient deteriorated, his weakness became worst and partial motor seizures appeared. Biopsy of one of the lesions showed macrophages filled with amastigotes. Finally, he developed an epileptic status and died as a consequence of sepsis. Before dying, a cerebrospinal fluid (CSF) sample was obtained, where trypomastigotes were found as well.

\section{Patient 3}

A 35-years-old male, HIV positive, who had not received antiretroviral therapy. He was admitted into the ward because of a sudden weakness on the left side of his body, which had started ten days before his assessment.

Neurological examination disclosed left-sided weakness and mild sensory loss.

Laboratory tests were unremarkable. A computed tomography (CT) of his brain showed a hemorrhagic lesion of $50 \times 40$ $\times 26 \mathrm{~mm}$ in volume, located at his right parietal lobe. A thorough cardiological examination and clotting blood tests were normal.

The patient partially recovered and was discharged with a minimal hemiparesis.

Two months later, he was readmitted because his weakness had became progressively worst along the last 2 weeks, and reported a few partial motor seizures and a moderate daily headache.

On clinical examination he showed a mild motor deficit and sensory impairment on his left side. Laboratory tests disclosed $551 \mathrm{CD} 4+$ lymphocytes $/ \mathrm{mm}^{3}$ and positive serological tests for 
Toxoplasmosis and Chagas' disease. A first blood sample searching for parasitemia was negative.

MRI showed that the original hemorrhagic lesion was smaller in size, but a new ring-enhancing lesion, of about $1 \mathrm{~cm}$ in diameter, appeared at its edge.

Treatment for toxoplasmosis was started; 7 days later the weakness became worst and a new TC disclosed another annular lesion located at the right basal ganglia.

A stereotactic biopsy of the parietal nodular lesion was performed; histological examination of the sample showed necrotic tissue and macrophages filled with amastygotes (Fig 2). At this time, a new blood examination was able to detect trypomastigotes.

The patient was put on Benznidazol $5 \mathrm{mg} / \mathrm{kg} /$ day, and antiretroviral drugs (d4T, 3TC and Nelfinavir). He was discharged and had a progressive but sustained improvement. MRI, five months later, revealed that all lesions had decreased in size. On follow up, 14 months after diagnosis, he showed mild motor sequelae and negative parasitemia. He is still on Benznidazol treatment.

\section{DISCUSSION}

The possibility that a dormant T. cruzi infection reactivates in a patient who, simultaneously, is affected by an HIV infection is quite reasonable knowing that the parasite is intracellular and becomes the guest of many cells after its innoculation in the acute period of the disease. It is noteworthy that the parasites are able to reach the central nervous system at the time of their first contact with its host ${ }^{11,12}$ and, thence, most probably, lodge in neurones and/or glia cells ${ }^{13,14}$. In normal conditions, the surveillance of the immune system takes control of them, but if for any reason the immune system fails, they will be allowed to reproduce and leave the host cell ${ }^{5-9}$. This sort of behaviour has been noted in patients whose immune system has been weakened by the employment of citotoxic drugs ${ }^{14,15}$.

In a previous communication ${ }^{7}$ we described 10 patients who had Chagas' disease and were asymptomatic until they were infected by the HIV virus. All of them developed cerebral tumour-like (pseudotumours) lesions when they had less than $126 \mathrm{CD} 4+$ cells $/ \mathrm{mm}^{3}$.

The present communication describes other three cases. Two of them had quite a similar behaviour than those already reported. However, the third patient was unique regarding his clinical presentation, the type of lesions found, the number of CD4+ cells and his response to treatment.

In regards to the first two patients, they behaved as most of the other patients described in the literature ${ }^{6,7,12,16,17}$ with a very poor outcome in spite of specific treatment, and like most of them, died shortly after diagnosis.

Opposite to this behaviour was the third patient. He disclosed several differences with the others. First, his clinical presentation was a lobar hemorrhagic lesion or, perhaps, a hemorrhagic infarct, which could not be explained by any circulatory or blood abnormality. It is worthy to note that it has been claimed that in chagasic patients brain trombo-embolism may occur in the absence of cardiac or arterial damage. Whatever the causes of the vascular event were, after 2 months of the initial manifestation, a MRI image suggesting a pseudotumour, was detected.

We do not know how the former lesion may be related to the later. The only finding that suggests a connection between them is the fact that they were in close proximity, contacting by their edges; one might speculate that the parasites, held in the blood of the hemorrhage, invaded part of the surronding tissues, later developing the pseudotumour.

The appearance of a third lesion, in the basal ganglia, strongly suggested an opportunistic disease and provided the rationale for the biopsy procedure, which made the diagnosis of Chagas' disease. The third difference is the number of CD4+ cells, being normal in this patient and suggesting a healthy state of his immune system. We do not have a clear explanation for this, either. Perhaps some type of impairment of the immune mechanisms, not reflected by the number of CD4+ cells, underlies this behaviour. Finally, he is the only one who showed an acceptable response to the specific treatment, which is currently sustained. Whether this favourable outcome is connected to the normal CD4+ cells count or not, is a yet unresolved question.

The cases described here, confirm that dormant Chagas' disease can reactivate in HIV patients in the form of brain pseudotumours. They also underline that these lesions can be the first opportunistic infection to appear. Therefore, Chagas' disease should be considered an AIDSdefining illness in Latin America; already some countries, Brazil and Argentina amongst them, have adopted this conception. Finally, it seems possible that this disease may appear in AIDS patients with an apparently normal immunological status, and that the anti-Trypanosoma treatment in combination with antiretroviral therapy, in this type of patients, may render more encouraging results.

\section{REFERENCES}

1. Prata A. Chagas' disease. Infect Dis Clin N Am 1994;8:61-76.

2. Coura JR. Chagas disease: what is known and what is needed- a background article. Mem Inst Oswaldo Cruz 2007;102(Suppl 1):S113-S122.

3. World Health Organization. World: estimated number of adults and children living with HIV / AIDS. Public Health Mapping and GIS. Geneve. Map Library, Oct/2005.

4. WHO/UNAIDS database. http://www.unaids.org/en/HIVdata/

5. Rosa M. Consenso de enfermedad de Chagas. Rev Argent Cardiol 2002; 70:43-51.

6. Sica RE, Pagano M, Segura M. Chagas' disease in acquired immunodefiency syndrome. Neurol Croatica 1996;45(Suppl 3):S15-S18.

7. Pagano M, Segura M, Di Lorenzo L et al. Cerebral tumour-like amer- 
ican trypanosomiasis in acquired immunodeficiency syndrome. Ann Neurol 1999;45:403-406.

8. Solari A., Saavedra H, Sepúlveda C et al. Successful treatmemt of Trypamosoma cruzi encephalitis in a patient with hemophilia amd AIDS. Clin Infect Dis 1993;16:255-259.

9. Ferreira M, de Andrade Nishioka S, Rocha A, et al. Acute fatal Trypanosoma cruzi meningoencephalitis in a human immunodeficiency viruspositive hemophiliac patient. Am J Trop Med Hyg 1991;45:723-727.

10. Cohen J., Tsai E, Ginsberg HJ, Godes J. Pseudotumoral chagasic meningoencephalitis as the first manifestation of acquired immunodeficiency syndrome. Surg Neurol 1998;49:324-327.

11. Hoof R, Teixeira R, Carvalho J, Mott KE. Trypanosoma cruzi in the cerebrospinal fluid during the acute stage of Chagas' disease. N Engl J Med 1978;298:604-606.

12. Silva N, O’Bryan L, Medeiros E et al. Trypanosoma cruzi meningoen- cephalitis in HIV infected patients. J Acquir Immune Defic Syndrom Hum Retrovirol 1999;20:342-349.

13. Corti M. AIDS and Chagas'disease. AIDS patient care. STDS 2000;14 581-588.

14. Ferreira M. Chagas' disease and immunosuppression. Mem Inst Oswaldo Cruz 1999;94:325-327.

15. Leiguarda R, Roncoroni A, Taratuto A L et al. Acute CNS infection by Trypanosoma cruzi (Chagas' disease) in immunosuppressed patient. Neurology 1990;40:850-851.

16. Montero A, Kohen J, Martínez E. Empyrical antitoxoplasma therapy in cerebral AIDS and Chagas invasion: presentation of two cases, survey of the literature and proposal of algorithm. Medicina 1998;58:504-506.

17. Del Castillo M, Mendoza G, Oviedo J, et al. AIDS and Chagas disease with central nervous system tumor-like lesion. Am J Med 1990; 88: 693-694. 